\title{
RADIOTHERAPY OF MALIGNANT INTRA-OCULAR NEOPLASMS \\ BY
}

\author{
H, B. STALLARD
}

LON DON

THE value of radiotherapy for glioma retinae is established. This tumour is very radiosensitive and when a quadrant or less of the retina has been affected by the growth treatment by radon seeds has caused the tumour to disappear and in a series of such cases treated at St. Bartholomew's Hospital there has been no recurrence in a period of follow-up from 1929-1948.

The results in the treatment of malignant melanomata by radon seeds are less fortunate. Metastatic carcinoma of the choroid is very radiosensitive and in some such cases it may be justifiable to use this treatment to conserve a little vision or to lessen the misery of the remaining months of the patient's life.

We have tried to strike the neoplasm with a dose judged to be adequate for its destruction without producing irremediable damage to the eye, and to bring the source of irradiation as close to the tumour as it is possible to obtain by surgical exposure. The insertion of a radon seed through the sclera into the growth has been abandoned for the technique of suturing radon seeds to the sclera over the site of the neoplasm, and we are now making trials with plaques of either platinum or silver $0.5 \mathrm{~mm}$. thick containing radium salt and curved to fit the sclera neatly over the site of the neoplasm and fixed by sutures passing through holes in the edges of the plaque and thence through the superficial layers of the sclera. The advantage of these will be a more even and accurate distribution of irradiation than is the case with a straight radon seed fixed at a tangent to the surface of the sclera, and a source of supply which remains constant and is available for immediate use for owing to labour difficulties there is in England to-day a delay up to 10 days in obtaining radon seeds.

The transparency of the eye media affords us special opportunities in this work of assessing the exact size of the neoplasm, of marking its boundaries by surface diathermy coagulation at operation and of following up its subsequent behaviour.

\section{DOSE}

For the permanent arrest and destruction of a malignant neoplasm it is necessary for the whole tumour-bearing area and indeed the tissues wide of this to receive a uniform intensity of irradiation effective for the particular growth during the whole time 
of the treatment. In the absence of accurate knowledge as to the exact dose that the tissues receive it is safer to give the maximum dose that the tissues will stand without incurring the risk of serious destructive changes and complications. A sub-lethal dose may inhibit the neoplasm for a period of time but it inevitably recurs and the success of further radiotherapy is jeopardized. It is therefore necessary to arrange the radium or radon in such a way as to produce an adequate intensity and homogeneity of irradiation.

Gamma ray therapy is measured in terms of the ionization in the air by the radiation, and such measurements have been taken in post-mortem material using small Sievert condenser ionization chambers at various sites in a new growth which had been subjected to interstitial radiotherapy. The unit of intensity has been defined as " the intensity of the radiations at a distance of $1 \mathrm{~cm}$. from $1 \mathrm{mg}$. point source of radium element (in equilibrium with its products) filtered by $0.5 \mathrm{~mm}$. of platinum." One curie of radon is the quantity of radon in equilibrium with 1 .gramme of radium and 1 millicurie is one-thousandth part of the this. The millicuriehour intensity (I) is given by the formula $I \frac{\mathrm{m}}{\mathrm{r}^{2}} 1 \mathrm{mc}$. $\mathrm{r}$ is the distance in centimetres of the treatment point from the source and $m$ is the strength of the radon source in millicuries.

"The roentgen is the quantity of $\mathbf{x}$ (or gamma) radiations which, when the secondary electrons are fully utilized and the effects of all scattered radiation avoided, produces in 1 c.c. of atmospheric air at $0^{\circ} \mathrm{C}$ and $76 \mathrm{~cm}$. mercury pressure such a degree of conductivity that 1 electro-static unit of charge is measured under saturation conditions."

From practical experience to date it seems better to use radon seeds as close to the neoplasm as possible in the treatment of malignant intra-ocular tumours rather than the employment of massive doses delivered from radium needles set in plaques or the radium " bomb." Such large doses in most cases have had a destructive effect on the eye, at the worst causing its loss through corneal necrosis and panophthalmitis. Depilation of the lashes and eyebrows, a burn of the conjunctiva and irradiation cataract are lesser ills.

To-date the number of cases of malignant intra-ocular neoplasms in which radiotherapy was considered justifiable have been too few and the dose tried too empirical and experimental to give as yet definite advice on this point. As a temporary guide it seems that a dose of $3,500 \mathrm{r}$ is adequate to destroy glioma retinae occupying one quadrant of the interior of the eye. 
At present (1948) radon seeds 1 and $2 \mathrm{mc}$. are used and these are stitched to the sclera at appropriate sites in the case of intra-ocular neoplasms. Their active length may be varied up to $6 \mathrm{~mm}$., their diameter is $1.4 \mathrm{~mm}$. and the screen is $0.5 \mathrm{~mm}$. of platinum.

The radioactivity of radon is reduced to half in 3.86 days, to onefifth in 8.8 days, and at the end of 40 days only 0.07 per cent. remains. This decay factor is constant. One millicurie is destroyed in 133 hours. The seeds are left in place 4 to 8 days depending on the dose required.

I am grateful to Mr. F. S. Stewart, Radium Department, St. Bartholomew's Hospital, for the following description of his findings and for his help and-ingenuity in designing a new radium applicator for the eye.

A review has been made of 22 cases successfully treated at St. Bartholomews' Hospital by radon seeds, in order to form an estimate of the radiation dose received at various points. In Table $A$ the cases are arranged according to the size of the glioma. The dimension listed as "diameter" is measured along the spherical surface of the retina; the height is measured from the level of the retina and is an estimate since accurate measurement of this dimension is impossible.

TABLE A

Radon Treatment of Glioma Retinae

\begin{tabular}{|c|c|c|c|c|c|}
\hline \multicolumn{2}{|c|}{ Size of Growth } & \multirow[b]{2}{*}{$\begin{array}{c}\text { No. and Strength } \\
\text { of Radon Seeds } \\
\text { (applied 168 hours) }\end{array}$} & \multirow[b]{2}{*}{$\begin{array}{c}\text { No. of } \\
\text { Cases } \\
\text { Treated }\end{array}$} & \multirow[b]{2}{*}{$\begin{array}{l}\text { Dose at Apex } \\
\text { of Growth }\end{array}$} & \multirow[b]{2}{*}{$\begin{array}{l}\text { Minimum Dose in Region of } \\
\text { Tumour, at a level } 1 \mathrm{~mm} \text {. } \\
\text { inside surface of Sclera }\end{array}$} \\
\hline $\begin{array}{l}\text { Diam, } \\
\text { mm. }\end{array}$ & $\begin{array}{c}\text { Height } \\
\text { (Estimated) } \\
\text { mm. }\end{array}$ & & & & \\
\hline 3 & $2 \cdot 5$ & $\begin{array}{l}1 \times 2 \mathrm{mc} \\
2 \times 1.1 \mathrm{mc}\end{array}$ & $\begin{array}{l}4 \\
2\end{array}$ & $\begin{array}{l}8800 r \\
9050 r\end{array}$ & $\begin{array}{l}23400 \mathrm{r} \\
22600 \mathrm{r}\end{array}$ \\
\hline $4 \cdot 5$ & 3 & $\begin{array}{l}1 \times 2 \mathrm{mc} \\
3 \times 1.1 \mathrm{mc} .\end{array}$ & $\begin{array}{l}1 \\
1\end{array}$ & $\begin{array}{r}7050 \mathrm{r} \\
10900 \mathrm{r}\end{array}$ & $\begin{array}{l}15700 \mathrm{r} \\
30200 \mathrm{r}\end{array}$ \\
\hline 5 & 3.5 & $1 \times 2 \mathrm{mc}$ & 5 & $5800 \mathrm{r}$ & $13900 \mathrm{r}$ \\
\hline 7 & 5 & $\begin{array}{l}1 \times 2 \mathrm{mc} \\
2 \times 2 \mathrm{mc}\end{array}$ & $\begin{array}{l}4 \\
1\end{array}$ & $\begin{array}{l}3500 \mathrm{r} \\
6300 \mathrm{r}\end{array}$ & $\begin{array}{r}9550 \mathrm{r} \\
12900 \mathrm{r}\end{array}$ \\
\hline 8 & $5 \cdot 5$ & $1 \times 2 \mathrm{mc}$ & 1 & $3350 \mathrm{r}$ & $7600 \mathrm{r}$ \\
\hline 10 & 7 & $2 \times 2 \mathrm{mc}$ & 2 & $4350 \mathrm{r}$ & $8500 \mathrm{r}$ \\
\hline 21 & 13 & $-4 \times 2 \mathrm{mc}$ & 1 & $2900 \mathrm{r}$ & $12300 \mathrm{r}$ \\
\hline
\end{tabular}

In all cases treated with $2-$ mc. seeds :-

Maximum Dose at a level $1 \mathrm{~mm}$. inside surface of Sclera 
The lowest dose received by any part of the tumour is at its apex and the value calculated is governed mainly by the figure estimated for the height. The apex doses shown are therefore only approximate, but they indicate that the smaller growths have generally received considerably higher doses than the larger. The fact that 7 successful results have been obtained with minimum tumour doses of $3,500 \mathrm{r}$ or less suggests that the amount of radon could safely be reduced for diameters below $7 \mathrm{~mm}$.

The dose received by the base of the glioma will, strictly speaking, depend on the combined thickness of sclera, choroid and retina at the site in question, but for simplicity the doses shown for the base are all calculated for a spherical surface $1 \mathrm{~mm}$. inside the outer surface of the sclera. The dose at this level is very uneven due to the proximity of the seeds and reaches a maximum of $38,500 \mathrm{r}$ in cases treated by a single 2-millicurie seed and approximately $50,000 \mathrm{r}$ where several seeds were used. The minimum dose within the area of the dose is in most cases 9,000 $\mathrm{r}$ or more, as shown in Table $\mathrm{A}$.

It is of interest to note that the outer surface of the sclera in direct contact receives as much as $125,000 \mathrm{r}$ in single-seed treatments and 150,000 in multiple-seed treatments.

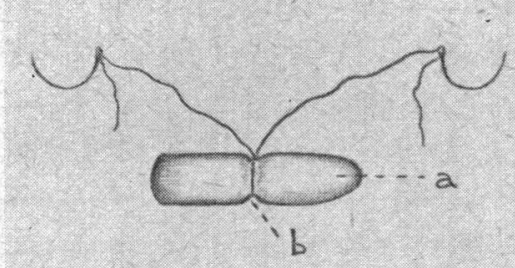

(i)

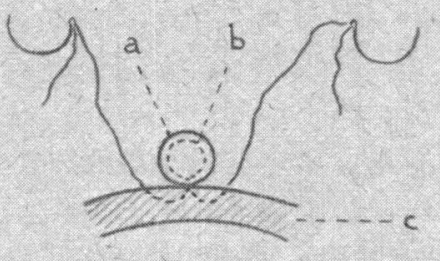

(ii)

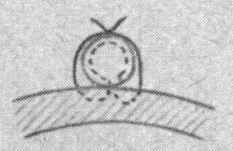

(iii)

FIG. 1.

Diagrams drawn to show the method of suturing a radon seed to the sclera. (i) $a$ Radon seed; $b$ Fine black silk thread tied in a groove filed through the platinum envelope circumferentially about its centre. Arterial needles are attached to the free ends. (ii) The interrupted line represents the silk thread running in the groove around the radon seed and then passing through the superficial layers of the sclera, $c$. (iii) The ends are brought together over the seed and tied in the groove. 
In 1929 Foster Moore inserted a radon seed into an intra-ocular neoplasm through a scleral incision made with an angular doubleedged knife the exact width of which equalled the diameter of the radon seed. The point of the knife entered the base of the neoplasm and on its withdrawal a radon seed in a special holder was introduced point first into the incision. In the case of malignant melanoma of the choroid the solid growth was apt to be pushed on in front of the blunt tip of the radon seed. Fig. 1 shows the

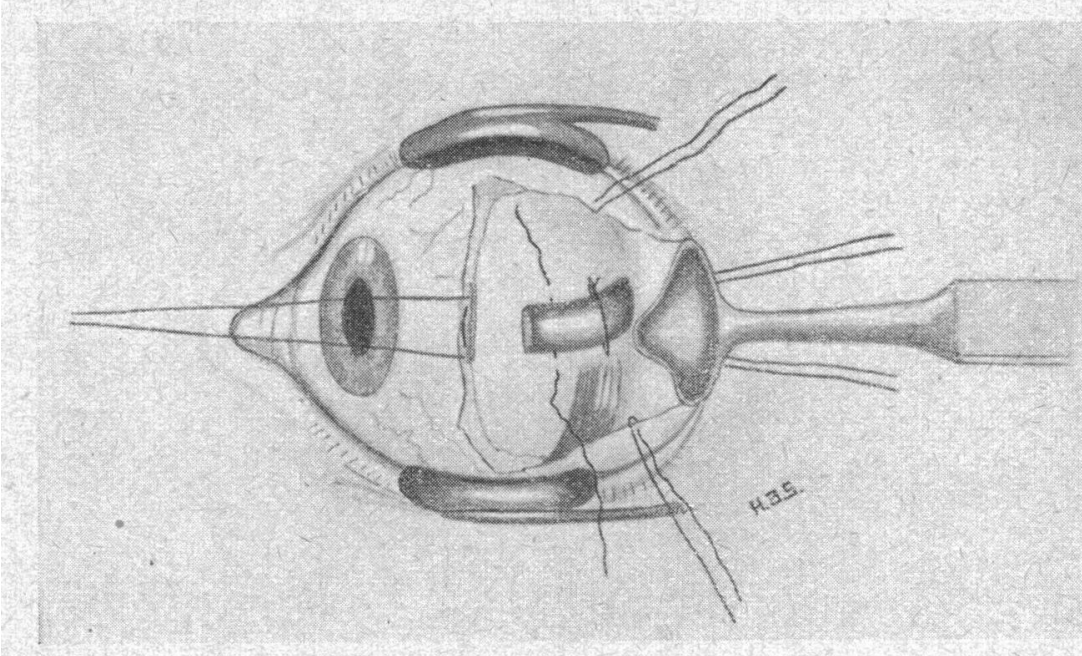

FIG. 2.

Glioma retinae of left eye at the temporal edge of the optic disc. The external rectus has been divided and the inferior oblique exposed. A stent strip moulded to the sclera and containing a 2 mc. radon seed is applied and held in place by two sutures.

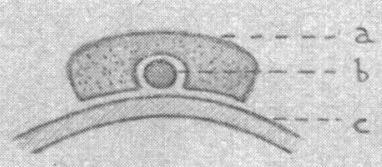

FIG, 2A,

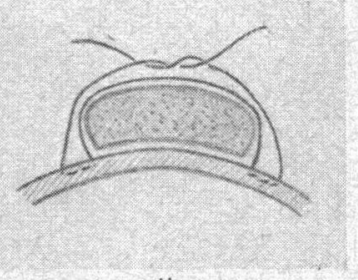

ii

i. Cross section through end of strip of stent holding radon seed; (a) Strip of stent dental wax moulded to sclera; (b) Radon seed embedded in stent; (c) Sclera. ii. Method of suturing stent strip to sclera in front of and behind equator. 
technique I have used for suturing a radon seed to the sclera, and Fig. 2 that of suturing to the sclera a stent strip, with an embedded radon seed, or 2 seeds, so that the radon lies close to the optic nerve sheaths at a point where suturing the seed directly to the sclera affords considerable technical difficulties.

Fig. 3 shows a shallow platinum or silver radium container $0.5 \mathrm{~mm}$. thick curved to fit the sclera and sewn to it.

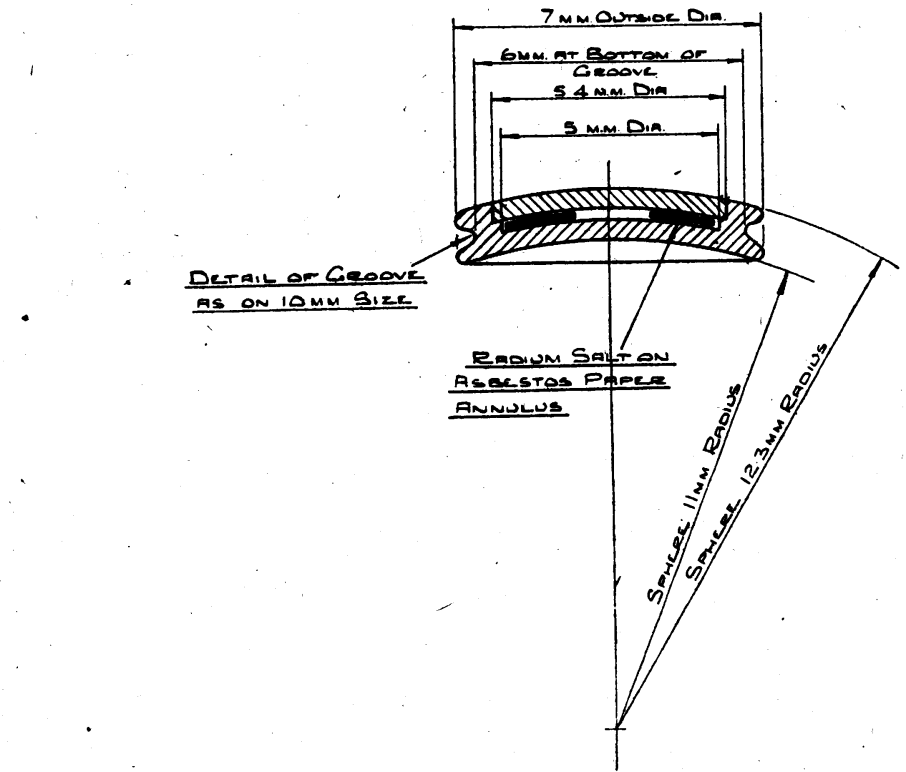

Sectional view of eye applicator $5 \mathrm{~mm}$. in size.

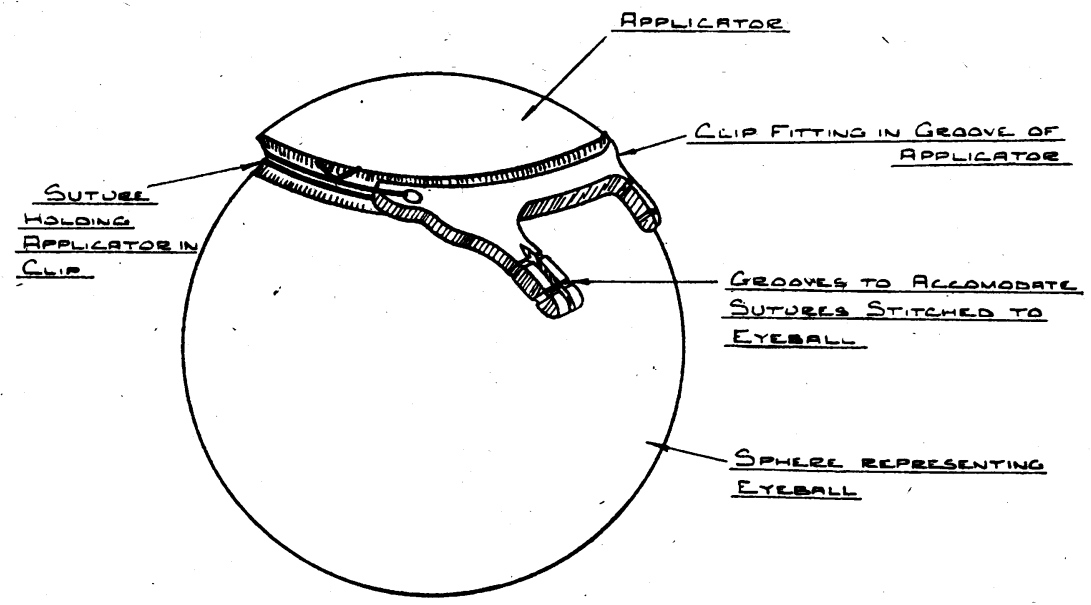

FIG. 3.

Radium applicator for attachment to sclera. 


\section{REACTION OF GLIOMA RETINAE TO RADON}

About the third day after the application of radon, parts of the neoplasm, particularly at its periphery, become more densely white. The appearance is comparable to flakes of curdled milk,

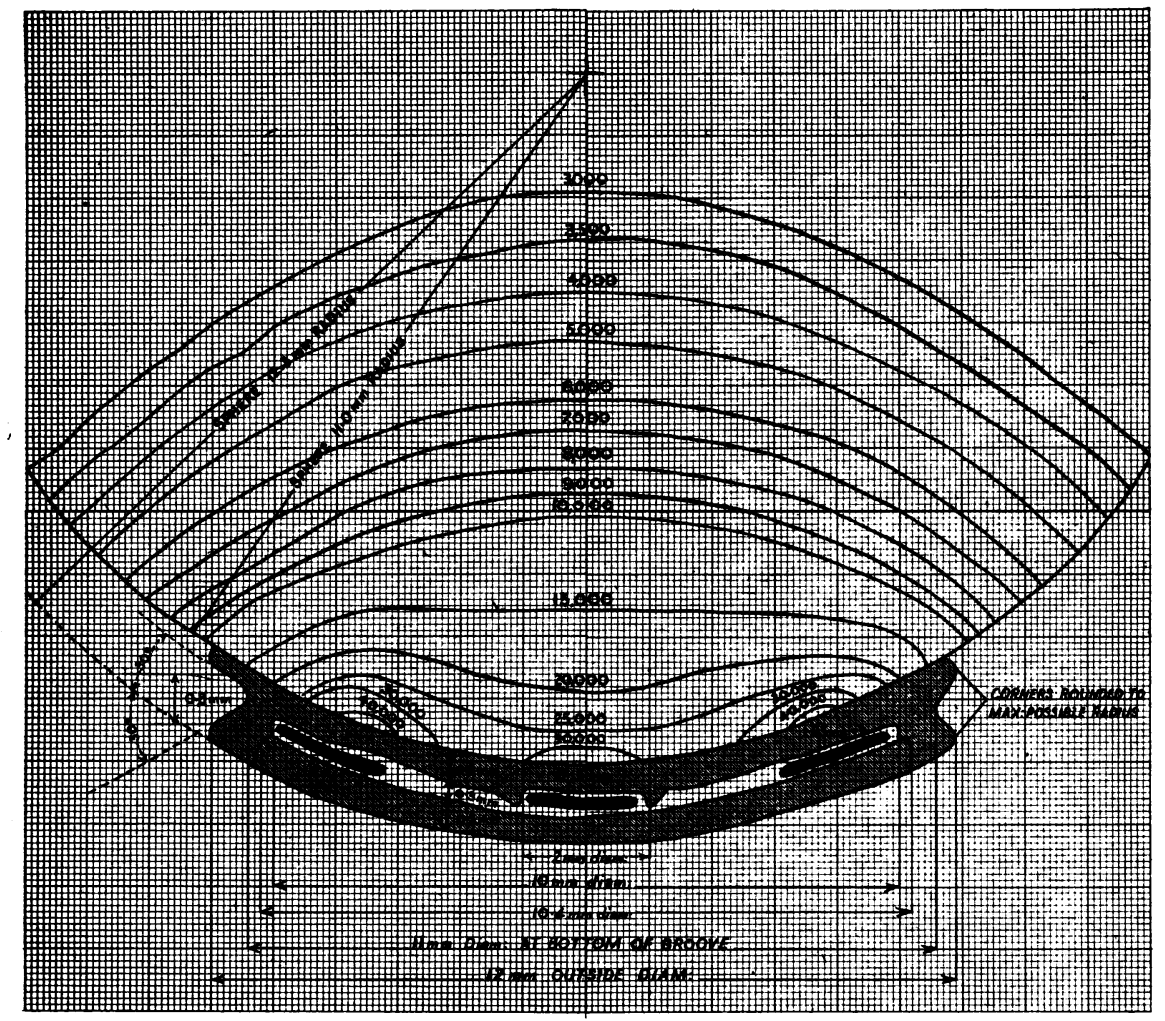

FIG. 4.

the glioma retinae looking like flocculent cream cheese in its preoperative state. In one or two weeks some of these dense white flakes become separated from the main mass of the neoplasm and the majority remain suspended near it. Rarely does such a flake gravitate in the vitreous to a place remote from the neoplasm, where it ultimately becomes absorbed.

Shrinkage of a successfully irradiated neoplasm is chiefly evident in the second and third week and continues till the eighth to tenth week. The periphery of the neoplasm is the first to be absorbed. 
There may remain at the centre some greyish-coloured degenerative material for several months in cases where the neoplasm occupies about a quadrant of the globe. The scar at the site of application of a radon seed is characteristic (Fig. 5). It is flat, has a crenated edge fringed with pigment, and the centre is dense

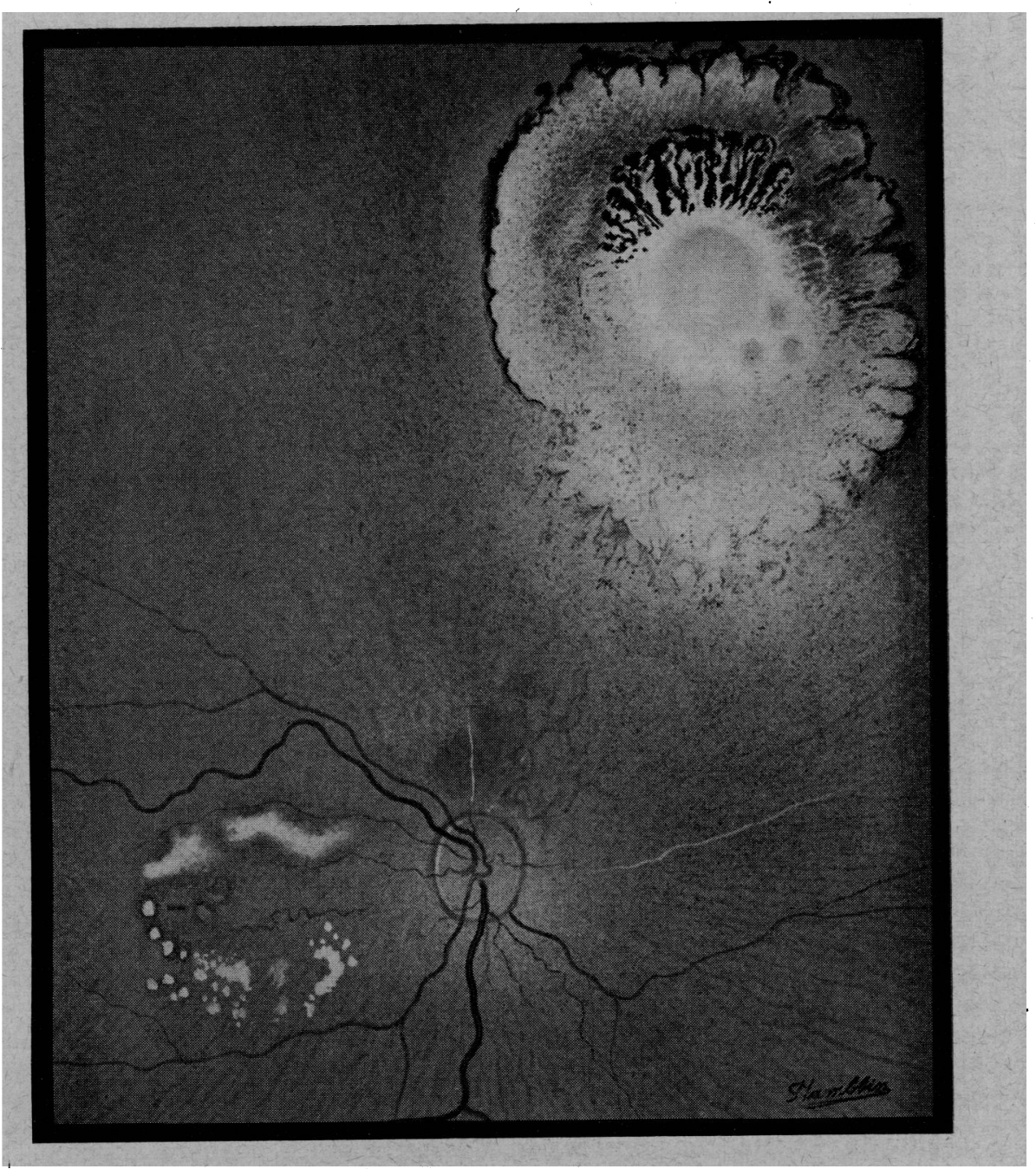

FIG. 5.

Glioma retinae. Right eye. Mass in upper nasal quadrant has been successfully irradiated. The scar in the retina and choroid is characteristic of an irradiated area. It has a crenated pigmented edge and the adjacent fundus shows fine pigment stippling. The retinal vessels are occluded in the upper nasal quadrant and some greyish exudates are around the macula. 
white. The surrounding fundus is finely stippled as if peppered with pigment. The retinal vessels in the region of the neoplasm are occluded.

These changes are produced at the site of application of the seed. In a case of glioma at the left macula a 2 mc. radon seed was purposely placed away from the macula at the equator in the 2.30 o'clock meridian. The neoplasm disappeared from the macula leaving only a faint greyish discoloration, which was indeed difficult to detect in comparison with a normal fundus, whereas the site of application of the radon seed showed the characteristic changes described above and shown in Fig. 5 . In the case of a large neoplasm a second application of radon may be necessary, but it is as well to wait for at least three months after the first application before deciding on this course.

For a description of the effects of radium on other ocular structures the reader is referred to Radiant Energy. (Brit. Jl. Ophthal., Monograph Supplement, 1933.)

\section{RADIUM APPLICATORS}

The use of radium in place of radon would be advantageous in avoiding the delay incurred in the preparation of the radon seeds. The conventional form of radium needle is, however, far too long for use in a similar manner to the seeds and it is proposed to use a new type of radium applicator as described below.

These applicators (see Fig. 3) have a platinum casing in the form of a segment of a spherical shell $1.3 \mathrm{~mm}$. thick, the inner radius of curvature being $11 \mathrm{~mm}$. to allow the device to be applied closely to the sclera. The casing is hollow, with a wall thickness of $0.5 \mathrm{~mm}$., leaving a cavity $0.3 \mathrm{~mm}$. in width. A range of sizes of applicator suitable for irradiating circular areas of the retina from 2 to $20 \mathrm{~mm}$. in diameter is proposed, and according to the area to be irradiated, the cavity contains an asbestos paper disc or annulus (or both) impregnated with radium salt. The wall thickness of the casing is sufficient to absorb all alpha and beta radiation so that the irradiation is purely by gamma rays.

The applicator is secured by sutures to the sclera. A groove is made on the edge of the casing and a semi-circular clip, with projecting lugs which can be sutured to the sclera, is made to fit the groove. Several interchangeable clips of different lengths are made for each applicator so that the sutures can always be made near the equator, no matter in what part of the globe the glioma is situated.

The radium loading has been calculated to give a dose of approximately $3,500 \mathrm{r}$ in one week (168 hours) at the apex of the growth. (For this purpose, the height of the glioma has been assumed to be seven-tenths of the diameter.) The distribution of the radium 
over the surface treated has been chosen so as to make the dose as uniform as possible at the surface of the retina. Taking the $10 \mathrm{~mm}$. diameter as an example, the dosage distribution is as shown in Fig. 4.

[The applicators are made by Messrs. Johnson, Matthey and Co., Ltd., to whom acknowledgment is made for collaboration in the technical aspects of the design.]

\section{CLINICAL FACTS}

This series consists of 15 cases treated by the application of radon seeds sewn to the sclera over the site of the glioma. Twelve were treated at St. Bartholomew's Hospital and 3 at the Moorfields Eye Hospital from 1934-1948 (see Table A). There were 8 males and 7 females. Their ages were between 4 months and 3 years, 6 were under one year old, 6 between 1 and 2 years and 3 between 2 and 3 years of age.

Fourteen were bilateral and one unilateral. The right eye was treated by radon in 7 cases and the left eye in 8 . The size of the neoplasm was over $\frac{1}{2}$ the interior of the globe in 1 case, nearly $\frac{1}{2}$ in 1 , and $\frac{1}{4}$ in 2 . There were 4 separate islands of glioma in 2 cases, 3 in 3 cases and 2 islands in 1 case. There were single masses of growth in 8 cases. The macula was the site of an island of growth in 4 cases.

It is important to search the periphery of the fundus very carefully, for small hemi-spherical masses about $15-3 \mathrm{~mm}$. in diameter were seen at the ora serrata in 4 cases. Furthermore it is important to examine the fundus at monthly intervals for a few years to discover islands of glioma arising in parts remote from the original neoplasm treated by radon. Such were found in 3 cases, one 5 months after irradiation, another 4 months later and the third one month after the application of radon seeds to 2 islands of glioma.

The dose of radon and the number of seeds were planned according to the size of the neoplasm. In 2 cases a single application of one 2 millicurie seed was made; in 4 cases 3 seeds were used and in 1 case 4 seeds. Two applications were necessary in 6 cases and 3 applications in 2 cases; and 3 of these were for a new island of glioma arising at a later date and remote from the site of the original growth. In 4 instances the second and third applications of radon were made at the site of the original growth because the destructive effect of the initial application of radon was considered doubtful. Although the changes in the neoplasm made by effective irradiation were evident on ophthalmoscopic examination between the 3rd and 8th day after irradiation and the neoplasm may disappear in 1 to 2 months it is, in some cases of large masses of growth, necessary to wait 5 or 6 months after radon treatment to 
be sure that the effect is complete. The site where the seed is sewn to the sclera shows in the fundus a characteristic white and pigmented scar with a crenated edge which appears about the 7 th month and is well formed 14 months after irradiation.

If the seed is placed a little remote from the island of glioma, for instance about $3 \mathrm{~mm}$. above or to the temporal side of a neoplasm about $3 \mathrm{~mm}$. in diameter at the macula (as in Case 6), the site of the irradiated growth will appear as a faint greyish discoloration and the position of the radon seed be shown by the characteristic scar described above.

\section{COMPLICATIONS}

(1) Cataract.-In 5 cases irradiation opacities occurred in the lens, in 4 of these the changes were in the centre of the posterior cortex and up to about $1.5 \mathrm{~mm}$. in diameter. In case (11) opacities began 13 months after irradiation and over a period of 6 years extended slightly from the equator of the lens at 2.30 o'clock in direct line with a $2 \mathrm{mc}$. radon seed which had been sewn to the sclera at the ora serrata.

In the 4 children with central posterior cortical opacities $4 \times{ }^{\circ} 2$ mc. radon seeds had been placed just behind the equator in one case; $3 \times 1.1 \mathrm{mc}$. seeds at the macula in one case; in another case on 2 occasions at 3 months interval a $1.1 \mathrm{mc}$. seed had been placed above the optic disc a second $1.1 \mathrm{mc}$. at the equator and one year and nine months later a 2 mc. seed was placed below the disc; and in the 4 th one $2 \mathrm{mc}$. seed and then $2 \times 2 \mathrm{mc}$. at 6 months interval were placed over the macula and adjacent to the temporal edge of the dural sheath of the optic nerve. In these cases the onset of lens changes after irradiation was 2 years and 2 months, 11 years and 6 months, 4 years and 9 months, and 5 years and 9 months respectively.

In case (1) the lens opacities have gradually spread in the posterior cortex from 1936-1948 and together with peri-macular exudates vision has become reduced to 6/60. Despite this handicap he has completed his education at Manchester Grammar School and passed School Certificate.

(2) Retinal changes. (a) Exudates.-Greyish irregular-shaped flecks of exudate occurred at and around the macula in 5 cases. In 4 of these relatively heavy doses of radon had been used behind the equator, $4 \times 2$ mc. seeds in 1 case; in a second case applications consisting of $2 \times 1 \cdot 1 \mathrm{mc}$. were given on 2 occasions and $1 \times 2 \mathrm{mc}$. on one oecasion; applications of $3 \times 2 \mathrm{mc}$. and $2 \times 2 \mathrm{mc}$. in a third case; and in the fourth case one application of $4 \times 2 \mathrm{mc}$. and 7 months later $2 \times 2 \mathrm{mc}$. were used. In the fifth case one $2 \mathrm{mc}$. was placed above and to the temporal side of a macular growth. In this 
last case the distribution of the exudates ultimately resembled those seen in retinitis circinata. The onset of these changes after irradiation was 2 years and 2 months, 1 year and 10 months, 11 months, 7 months and 9 years respectively. The exudates persist for a number of years, up to 11 years has been observed to-date. The occurrence of this complication has been noted in the series only when radon was used behind the equator. It has, however, been seen in a patient suffering from a lesion of haemangio. gliomatosis retinae at the ora serrata which Foster Moore treated with radon seeds.

In one of these cases associated with central lens changes vision fell to $6 / 60$, in another from $6 / 18$ to $6 / 24$ and the remaining 2 lost their sight through a severe vitreous haemorrhage in one case and total retinal detachment in the other.

(b) Haemorrhages.- Retinal haemorrhages were a late complication in 6 cases. In one instance 2 very small haemorrhages occurred near the equator in the upper nasal quadrant 3 years after irradiation of a neoplasm at the macula and these have persistedat this site for over 8 years. In the other 5 cases the radon seeds had been placed near the main branches of the central retinal vessels within a few millimetres of the optic disc and haemorrhages occurred 6 months, 7 months ( 2 cases), 11 months, and 1 year after irradiation.

In one patient, Case (3), the haemorrhage was so severe that it extended into the vitreous, causing retinitis proliferans.

(c) Retinal detachment occurred in 4 cases. In 2 of these the growth filled about half the eye in case (4) and more than this in case (5). Nearly half the interior of the eye was occupied by 4 islands in case (12) two of which were large. The dark greyish colour of the detachment suggested that between the retina and choroid there existed a mass of cell débris. In none of these cases followed up since 1936 and 1937 has there been any evidence of recurrence of the glioma.

\section{RESULTS}

In all 15 cases the islands of glioma were effectively irradiated by radon seeds.

One child, Case (7), died about one year after successful irradiation of a single island of glioma, of which there was no trace on pathological examination after death. The cause of death was not discovered. It was suggested that it might have resulted from the cerebral effects of deep $\mathrm{X}$-ray therapy given to the orbit from which the other eye had been excised.

Case (10) was evacuated from St. Bartholomew's Hospital at the outbreak of war, went to Manchester and in January, 1940, on account of complicated glaucoma and the appearance of a suspicious mass near the optic disc the eye was excised. 
H. B. Stallard

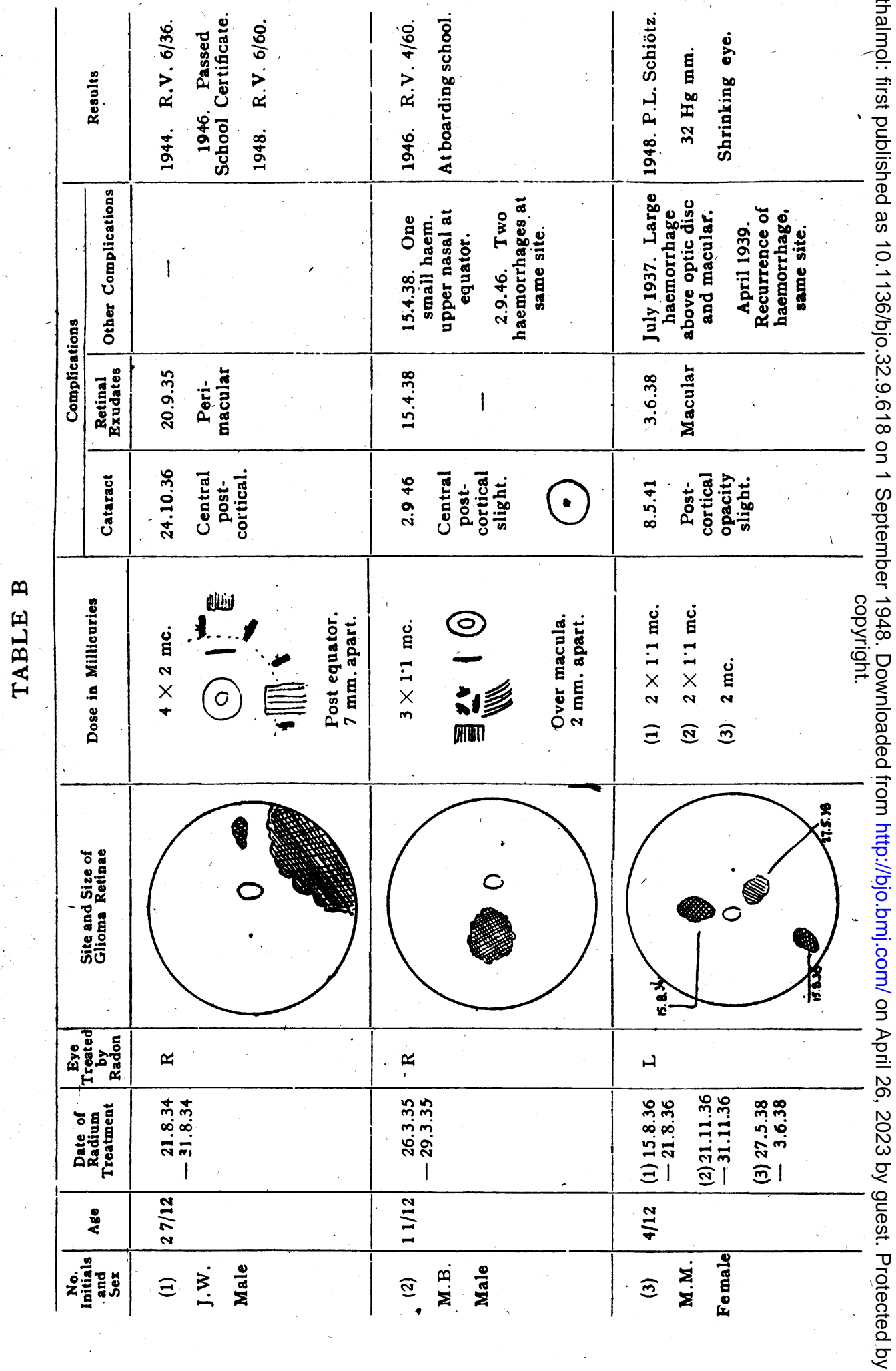


RADIOTHERAPY OF MALIGNANT INTRA-OCULAR NFoplasmS

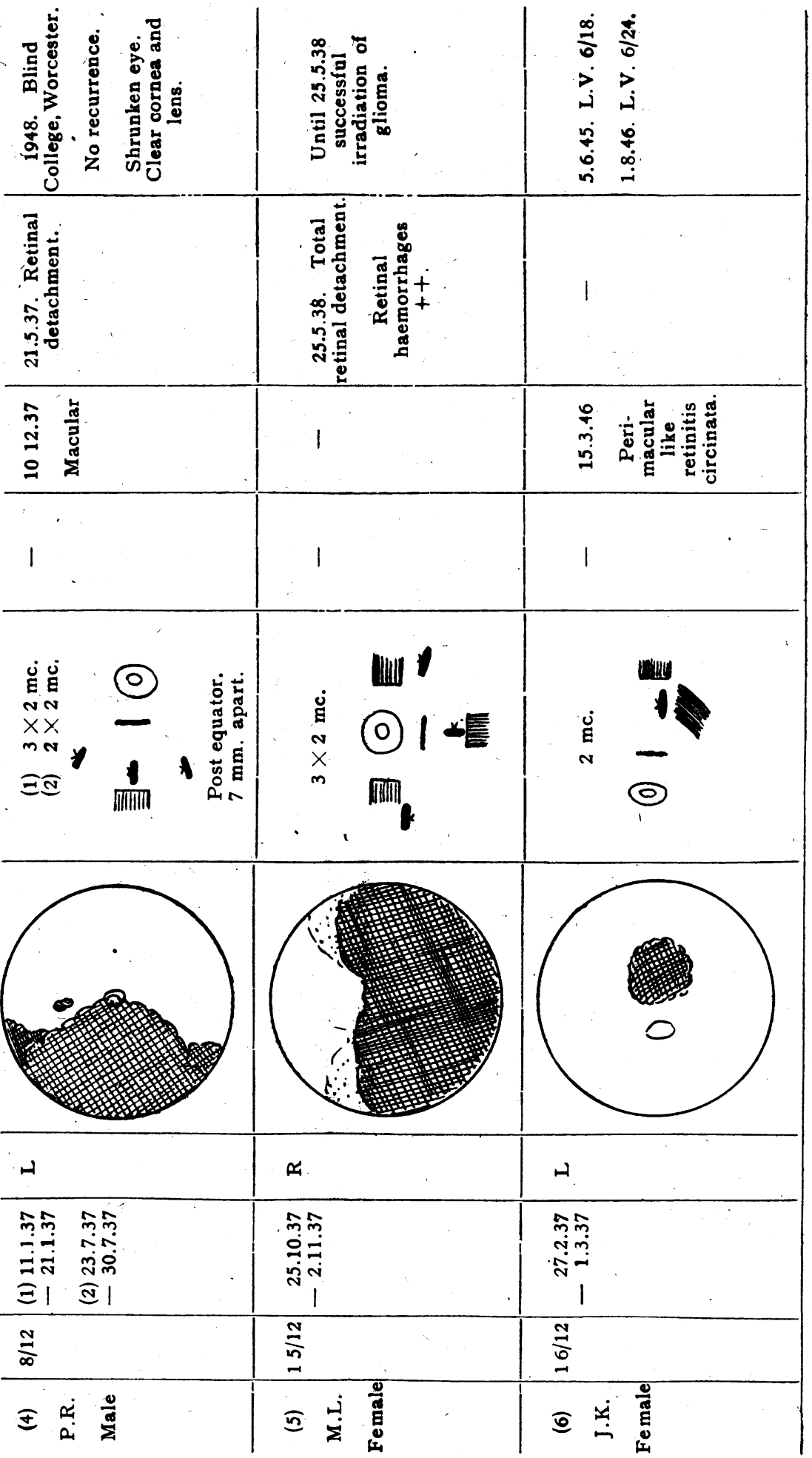


H. B: Stallard

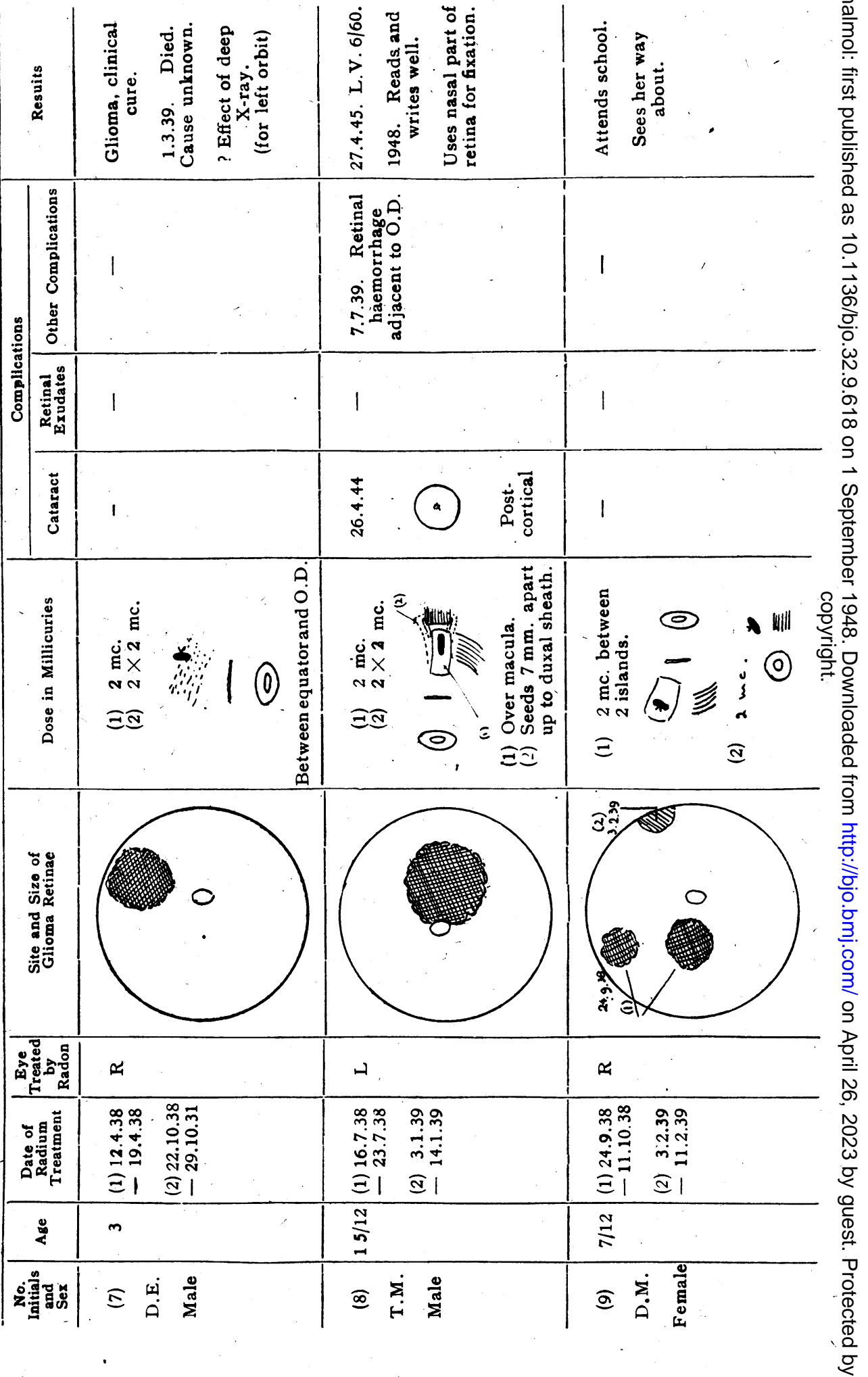


RADIOTHERAPY OF MALIGNANT INTRA-OCULAR NEOPLASMS

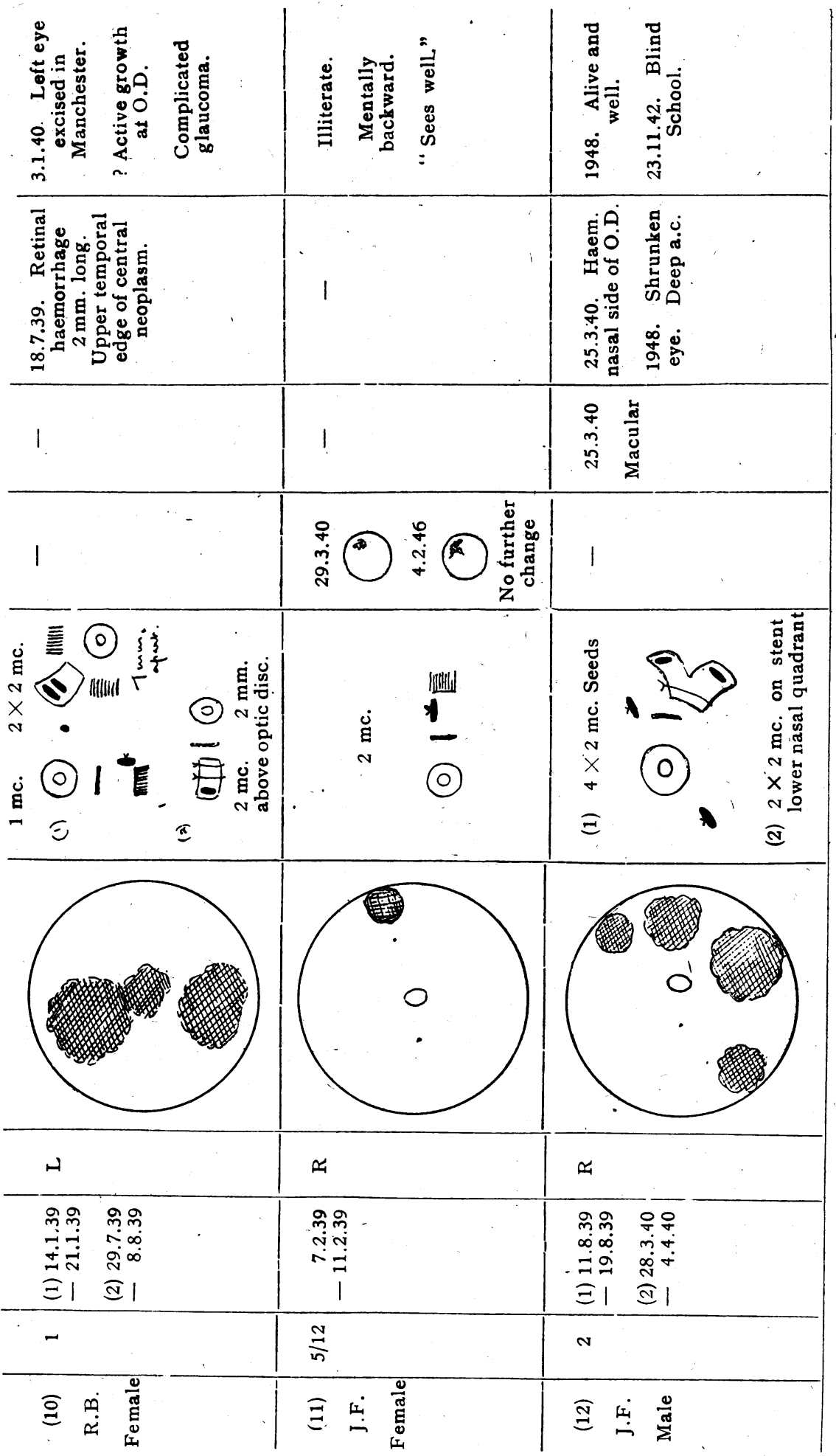




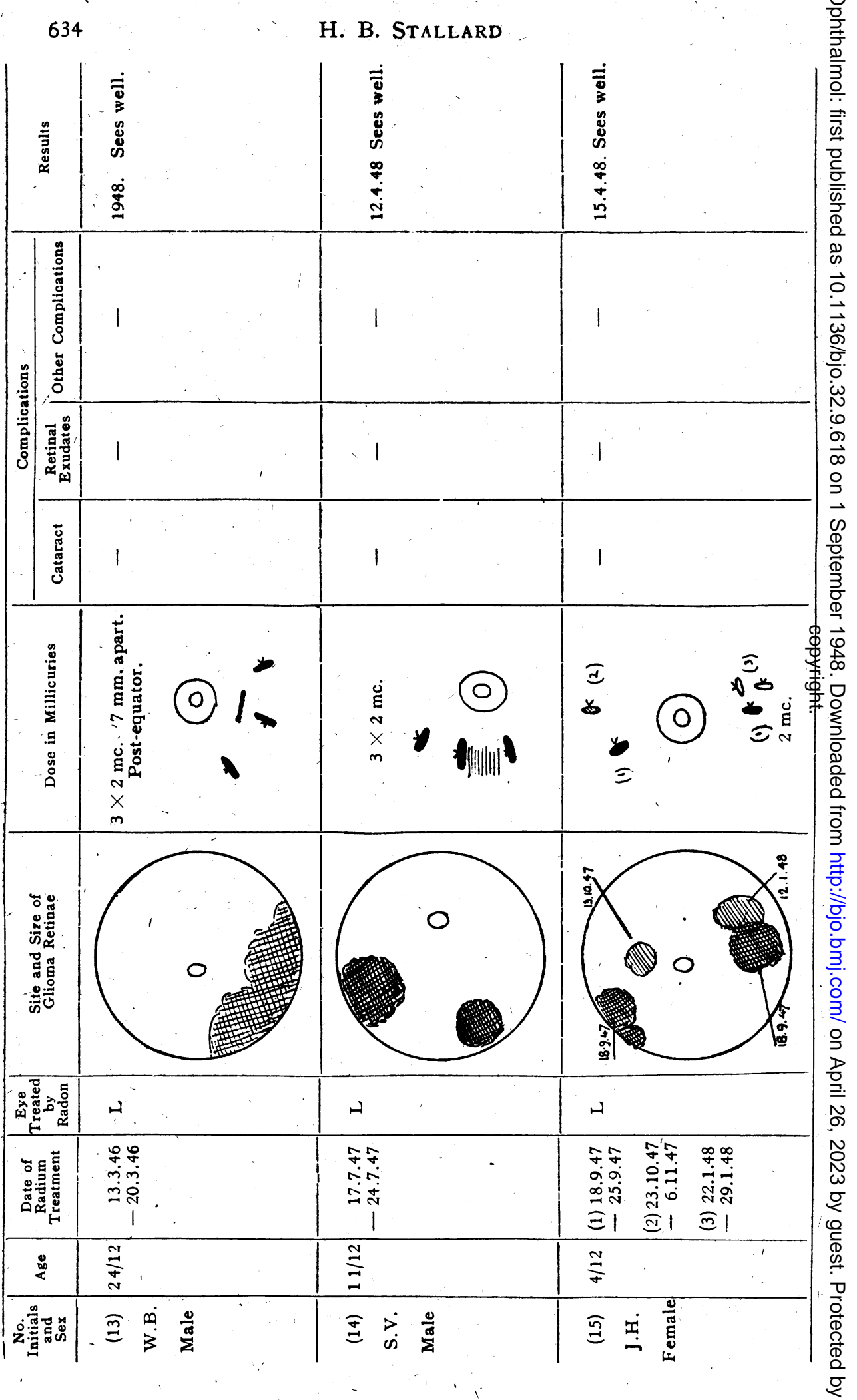


Case (5) was the only unilateral case treated by radon seeds in this series. More than half the interior of the eye was occupied by the neoplasm. Excision of the eye had been refused by the parents. It seemed from ophthalmoscopic appearances that the neoplasm had been successfully irradiated. Seven months after this treatment a total retinal detachment and severe retinal haemorrhages occurred.

In Case (4) about half of the interior of the eye was filled with the neoplasm. Five months after irradiation the retina was detached at the site of the neoplasm and ultimately the eye shrank. The cornea and lens have remained clear to-date for 11 years, there has been no recurrence of the neoplasm and the boy has been in good health. He is doing well at the Normal College for the Blind, Worcester.

Case (12) had 4 islands of glioma, 2 of which were large. He had $4 \times 2 \mathrm{mc}$. seeds applied in August, 1939, and one in March, 1940. In November, 1942, the eye became soft, shrunken, the anterior chamber deep, the lens opaque and there was no perception of light. To-date April, 1948, he is alive and well.

Four children (Cases 2, 6, 8 and 9) had neoplasms at the macula. In Case (6) a 2 mc. radon seed was purposely placed away from and above and to the temporal side of the neoplasm at such a distance that the growth was within effective range of the radon seed. As mentioned above the typical scar in the retina and choroid which occurs at the site of the seed did not in this case involve the macula. Except for slight greyish discolouration there was no ophthalmoscopic change at the macula until 9 years after irradiation when some exudate appeared. This child had 6/18 vision which has fallen to $6 / 24$ on account of the exudates. It is interesting to note that vision has been sufficient for school work in the other 3 cases of macular involvement where a radon seed was placed over the macula and the characteristic scar appeared at this site. M.B. (Case 2) saw 4/60 and is doing well at a boarding school. T.M. (Case 8) sees 6/60 with the nasal part of the fundus, writes and draws clearly and reads fluently from a book held about 6 inches from his eye and to the temporal side. J.W. (Case 1), treated in 1934, had good vision until increasing posterior cortical opacities reduced this to 6/60. He has attended Manchester Grammar School and passed school certificate. The lens is to be extracted.

J.F. (Case 11) is illiterate and mentally backward, she attends school and it is evident that she sees reasonably well playing games. Of the remaining 4 children 3 are at present too young for accurate visual acuity tests, but it is clear that they see objects about them and when they have become old enough have been able to dress, feed themselves and join in games with other children.

To sum up. In this series there has been one death (cause unknown) whose eye was successfully irradiated. Four have become blind, in 3 of these the irradiated eyes shrank, one after a severe vitreous haemorrhage and retinitis proliferans and the other 2 after retinal detachment, and the fourth had her eye excised in Manchester because of a suspected recurrence. In one case the disease was unilateral, a retinal detachment and retinal haemorrhages destroyed the sight of the irradiated eye. The remaining 9 (60 per cent.) children have attended schools and have enjoyed sufficient sight for educational needs, to see their way about and to participate in most games.

\section{COMMENTARY}

The treatment ${ }^{-}$of glioma retinae by radium is under trial, with changes in technique, and the dose is at present empirical. It seems that a dose of $3,500 \mathrm{r}$ is effective in destroying this very radiosensitive neoplasm. The method of interstitial irradiation 
by the insertion of a radon seed through the sclera into the substance of the neoplasm has been abandoned for that of suturing the seed, or several seeds at appropriate intervals of $7 \mathrm{~mm}$. to the sclera over the site of the glioma marked out on the sclera by surface diathermy and checked by ophthalmoscopic examination. Trial is now being made with radium plaques of silver or aluminium $0.5 \mathrm{~mm}$. thick containing radium salt, shaped to the radius of curvature of the sclera and secured thereto with fine silk sutures.

The results of treatment are good when the neoplasm occupies a quadrant or less of the globe and the visual result is better when the islands of glioma are at or in front of the equator. In the case of a growth at or near the macula and optic disc it is preferable, in order to avoid the dense choroido-retinal scarring which occurs immediately beneath the site where the radium is placed on the sclera and damage to the larger branches of the central retinal vessels, to place the source of radium a little remote from the growth, towards the periphery but leaving it within the range of effective irradiation.

Serious complications such as retinal detachment, large intraocular haemorrhages and ultimately shrinkage of the globe occur in cases where about half or more of the interior of the eye is occupied by the neoplasm and when it has been necessary to place radon seeds over the large branches of the central retinal vessels as these curve near the optic disc.

In my opinion it will be justifiable in future to treat unilateral cases of glioma by radium if the neoplasm occupies a quadrant of the globe or less. However, it is seldom that an infant is brought for examination at such a stage and generally half or more of the retina is destroyed before attention is drawn to the disease.

\section{MALIGNANT MELANOMA OF THE UVEAL TRACT}

Stanford Cade writes "Malignant melanomata are radioresistant tumours and their treatment by radiation is both difficult and disappointing. It is, however, unfortunate that radioresistance-a comparative term used to indicate the degree of sensitivity to radiation of one tissue as compared with another-should have been given a meaning synonymous with that of 'unsuitability for radiation" "and Ellis comments "this attitude (that melanomata are radioresistant and unsuitable for radiotherapy) moreover seems to be so universally adopted at radiotherapeutic centres in various parts of this country and America, that it would seem the time is ripe for suggesting the contrary opinion, for which there can be adduced a good deal of evidence of an incontrovertible kind, that some melanomas, at any rate, are radiosensitive." 
H. Barkan commented in 1934 that the literature contained no case of malignant melanoma cured by radium. Transient regression of the neoplasm has been noted by Parker, Stokes, Janeway and Birch-Hirschfeld. Microscopic examination of excised eyes showed extensive regression but there remained small areas of well-stained and active tumour cells.

To date, the material for radiotherapy has been too small to assess the relative radiosensitivity of the various types of cell found in malignant melanomata-e.g., spindle-cell $(a)$ and $(b)$, fascicular, endothelial, and mixed-celled neoplasms. It is evident that better results are obtained when the growth is lens-shaped, has not ruptured Bruch's membrane, and is in the vicinity of the equator. The results are appreciably less fortunate when the neoplasm involves the ciliary body and when it is-adjacent to the optic disc.

Radiotherapy is justifiable in rare cases of bilateral malignant melanoma of the choroid and I think in the future this may be so for some cases of unilateral growths seen in the early stages. The following case report is an instance of a bilateral malignant melanoma of the choroid in which the neoplasm in the second eye has remained inactive 9 years after irradiation.

E.H., aged 36 (in 1939), had his left eye excised for malignant melanoma of the choroid in April, 1939. Microscopic examination showed a pigmented spindlecelled neoplasm. In the right eye a lens-shaped greyish-brown swelling was seen on the nasal side about the equator between the 2.30 o'clock and 4 o'clock meridians. Its size was assessed as carefully as possible by ophthalmoscopic examination and at operation its limits were marked out by four surface diathermy applications to the overlying sclera and checked by the ophthalmoscope. Within this marked quadrilateral area whose sides measured $8,5,8$ and $3 \mathrm{~mm}$. respectively $3 \times 2$ mc. radon seeds were sewn to the sclera. The depth of the growth had been approximately assessed by the ophthalmoscope at $4 \mathrm{~mm}$.

In eight weeks the neoplasm was reduced to a flat plaque and it has remained thus with no sign of activity to-date April, 1948. The vision of this eye is $6 / 5$. There are a few vacuoles in the upper nasal quadrant of the posterior cortex of the lens but these cause no visual disturbance.

Another case of a maingnant melanoma adjacent to the optic disc on the nasal side was successfully irradiated in 1940, has kept his eye to-date (1948) but some obliteration of small vessels in the optic disc caused optic atrophy to become evident 7 to 8 weeks after irradiation.

Three other cases of malignant melanoma of the choroid and one of the ciliary body have been treated by radon seeds at St. Bartholomew's Hospital. In one case in 1932 there was a mushroom-shaped malignant melanoma of the choroid which had burst through Bruch's membrane just behind the equator. The neoplasm diminished in size after irradiation with 4 radon seeds and 5 months after operation it seemed likely on ophthalmoscopic examination that some viable neoplasm was still present and so 
the eye was excised. After excision the neoplasm measured $9.9 \times 7 \times 4 \mathrm{~mm}$. The area of effective irradiation as judged by microscopic evidence of chromatolysis, necrobiosis, degenerative changes and obliteration of the blood vessels was found in serial sections to be $8.5 \times 6 \times 2 \mathrm{~mm}$.

Another case of malignant melanoma of the choroid in an only eye was treated by $4 \times 1 \mathrm{mc}$. radon seeds on October 8 , 1935 , the growth shrank to a flat plaque and remained so till December, 1937, when it began to grow again. The lower half of the retina became detached and the vision reduced to hand movements. It seemed justifiable to attempt local excision after reflecting a scleral flap. This was done by a combination of surface diathermy along the lines planned for the scleral flap incision and a cutting diathermy needle in the choroid around the base of the neoplasm when this was exposed. The neoplasm was removed without loss of vitreous and with no apparent damage to the retina which was seen in the wound after removal of the growth and before tying the sutures in the scleral trap-door. This was done on December 17, 1937. The post-operative course was remarkably uneventful till a vitreous haemorrhage occurred during the third week. The patient was alive and well when he was last heard of in September, 1939. He could see his way about in familiar surroundings, but could not read. He declined to attend hospital for further follow-up examinations.

In another case of malignant melanoma of the choroid the growth was markedly reduced in size, the patient died about $1 \frac{1}{2}$ years later of some other disease. He was a Jew and his relatiyes refused post-mortem examination, so a valuable specimen was lost.

One case of richly pigmented malignant melanoma of the ciliary body between 2 and 5 o'clock was treated by $3 \times 2$ mc. radon seeds sutured to the sclera. The neoplasm shrank in 8 weeks to half its size. Fourteen weeks after operation pain, lacrimation, conjunctival congestion and photophobia made the patient request excision of the eye.

\section{METASTATIC CARCINOMA OF THE CHOROID}

If this occurs in an only eye or, as it rarely does, in both eyes, irradiation by radon seeds is successful and justifiable in so far that this procedure saves the eye and some measure of sight which the sufferer is able to enjoy before he dies.

I thank the following surgeons for recommending patients: Mr. Gibb, Mr. Neame, Mr. Doyne, Mr. Davenport and Mr. Rycroft (London); Mr. Stirling and Mr. MacNabb (Manchester); Mr. Holmes (Liverpool); Mr. Ashdown Carr (Derby); Mr. Gann (Peterborough); Mr. Aitchison (Newcastle-upon-Tyne); Mr. Galloway (Nottingham); and Mr. Colley (Bath).

I also thank Mr. Stewart and Mr. G. S. Innes, Radium Department, St. Bartholomew's Hospital, for valued advice. 
Point for Consideration in Use of the Stereoscope 639

In conclusion I express my lasting gratitude to my late chiefs. To Mr. Foster Moore for the privilege I enjoyed of assisting him in his pioneer work on this subject, for the stimulus of his clear and honest observations, and for his generosity in allowing me to treat some of his cases at St. Bartholomew's Hospital. To Sir John Parsons, that " Master " of the physiology and pathology of the eye, I owe a high example of the manner in which to seek academic truth.

\title{
REFERENCES
}

Cade, Stanford.-Malignant Disease and its Treatment by Radium. John Wright and Sons Ltd., 1940.

Ellis, F.-Brit. Jl. Radiol., Vol XII, pp. 327-352, 1939.

MOORE, R. Foster.-Brit. Jl.Ophthal., Vol. XIV, p. 145, 1930; Trans. Ophthal. Soc. U.K., 1933.

Ninth Ann. Rep. Nat. Radium Commission, 1937-8.

Stalla RD, H. B.-Radiant Energy, Brit. Jl. Ophthal., Monograph Supplement, 1933; Brit. Med. Jl., Vol. II, p. 962, 1936; Brit. Jl. Ophthal., Vol. XXII, p. 604, 1938; Eye Surgery, John Wright and Sons Ltd., 1946.

WALDMAN N.-Arch. of Ophthal., Vol. XXIII, p. 55, 1940.

\section{A POINT FOR CONSIDERATION IN THE USE OF THE STEREOSCOPE}

BY

\author{
FranK W. LÁW \\ LONDON
}

IT recently occurred to the writer that it would be of value to know the answer to the question "What happens to the inclination of the visual axes on moving the stereogram in a stereoscope towards or away from the observer?'? The question seemed simple; the answer was not obvious. Further, enquiry in various directions discovered the somewhat consoling result that the answer was not generally known; indeed, it had not been considered by most of those asked, which is surprising, in view of the common habit of sending a patient home to "do exercises with a stereoscope."

On investigating the subject it is soon apparent that the interocular distance is a factor of fundamental importance. This can be demonstrated by considering three diagrams (Figs. 1, 2 and 3) in which the stereogram card is depicted as placed at three different distances from the lenses of the instrument. Fig. 1 shows it placed at the focal plane; the emergent pencil of light has parallel rays, and the amount of convergence is independent of the interocular distance. In Fig. 2 the card is represented as nearer than the focal plane; the emergent pencils are divergent and greater inter- 